\title{
Cerebrovascular responses to carbon dioxide in children anaesthetized with halothane and isoflurane
}

To determine the effects of isoflurane and halothane on cerebrovascular reactivity to $\mathrm{CO}_{2}, 30$ children aged one to six years were anaesthetized with isoflurane or halothane in an air and oxygen mixture with an $\mathrm{FIO}_{2}$ of 0.3 . The end-tidal concentrations (0.5 minimum alveolar concentration (MAC) or 1.0 MAC) of isoflurane or halothane were age-adjusted. After achieving a steady-state at both 0.5 MAC and 1.0 MAC isoflurane and halothane, the end-tidal carbon dioxide tension $\left(\mathrm{PETCO}_{2}\right)$ was randomly adjusted to 20,40 , or $60 \mathrm{mmHg}$. Cerebral blood flow velocity (CBFV) and the cerebrovascular resistance index $(R I+)$ in the middle cerebral artery (MCA) were measured by a transcranial Doppler monitor. Three measurements of $\mathrm{CBFV}$ and $\mathrm{RI}+$ were obtained at each $\mathrm{PETCO}_{2}$ and isoflurane or halothane concentration. Any rise in the $\mathrm{PETCO}_{2}$ caused an increase in $\mathrm{CBFV}$ during both $0.5 \mathrm{MAC}$ $\left(r^{2}=0.99\right.$ and 0.99) and 1.0 MAC $\left(r^{2}=0.96\right.$ and 0.95) isoflurane and halothane anaesthesia, respectively $(P<0.05)$. The CBFV for isoflurane increased as $\mathrm{PETCO}_{2}$ increased from 20 to $60 \mathrm{mmHg}$ for both $0.5 \mathrm{MAC}$ and $1.0 \mathrm{MAC}(P<0.05)$. The $\mathrm{CBFV}$ for halothane increased as $\mathrm{PETCO}_{2}$ increased from 20 to

\section{Key words}

ANAETHESIA: paediatric;

ANAESTHETICS, VOLATILE: isoflurane, halothane;

BRAIN: cerebral blood flow;

CARBON DIOXIDE: tension, end-tidal;

MEASUREMENT TECHNIQUE: transcranial Doppler.

Received from the Department of Anaesthesia and the Research Institute, The Hospital for Sick Children, University of Toronto, Toronto, Ontario, Canada M5G 1X8. Winner of The American Academy of Pediatrics Housestaff Research Award, Section on Anesthesiology, Seattle, Washington, April, 1990.

Address correspondence to: Dr. Bruno Bissonnette, Director of Neuroanaesthesia, Department of Anaesthesia, The Hospital for Sick Children, 555 University Avenue, Toronto, Ontario, Canada, M5G 1 X8.

Accepted for publication 21 st May, 1991.
$40 \mathrm{mmHg}$ for both 0.5 MAC and 1.0 MAC halothane $(P<0.05)$, but did not change as $\mathrm{PETCO}_{2}$ increased from 40 to $60 \mathrm{mmHg}$ for both 0.5 MAC and 1.0 MAC halothane. The RI+ showed an inverse relationship with $\mathrm{CBFV}$ at each $\mathrm{PETCO}_{2}$ for $0.5 \mathrm{MAC}$ $\left(r^{2}=0.98\right.$ and 0.99) and 1.0 MAC $\left(r^{2}=0.76\right.$ and 0.53$)$ isoflurane and halothane, respectively $(P<0.05)$. The $C B F V$ did not differ significantly between 0.5 and 1.0 MAC isoflurane and halothane at corresponding $\mathrm{PETCO} \mathrm{O}_{2}$ values. The cerebrovascular response to $\mathrm{CO}_{2}$ at $20 \mathrm{mmHg}$ between $0.5 \mathrm{MAC}$ and 1.0 $M A C$ halothane was not significantly different. These data strongly suggest that isoflurane and halothane in doses up to 1.0 $M A C$ do not affect the cerebrovascular reactivity of the MCA to $\mathrm{CO}_{2}$ in anaesthetized, healthy children.

Afin de déterminer l' effet de l' isoflurane et de l'halothane sur la réactivité du système cérébrovasculaire au dioxide de carbone $\left(\mathrm{CO}_{2}\right), 30$ enfants agés de un à six ans anesthésiés avec de l'isoflurane ou de l'halothane dans un mélange d'air et d'oxygène à une concentration inspirée de 0.3 ont été utilisée. Les concentrations en fin expiratoire $(0.5$ concentration alveolaire minimum (MAC) ou 1.0 MAC) d' isoflurane ou d' halothane étaient ajustées pour l'age. Après avoir obtenu l'état d'équilibre à $0.5 \mathrm{MAC}$ et $1.0 \mathrm{MAC}$ pour chacun des gas, la tension en fin d'expiration du $\mathrm{CO}_{2}\left(\mathrm{PETCO}_{2}\right)$ était de façon aléatoire ajustée à 20,40, et $60 \mathrm{mmHg}$. La vélocité du débit sanguin cérébral (CBFV) ainsi que l'index de résistance cérébrovasculaire $(R I+)$ de l'artère moyenne cérébrale (MCA) ont été mesuré au moyen d'un Doppler transcranien. Trois mesures de CBFV et RI+ étaient obtenus pour chacune des $\mathrm{PETCO}_{2}$ au différentes concentrations d'isofiurane et d'halothane étudiées. Nous avons observé que la CBFV augmentait de façon logarithmique avec l'augmentation de la $\mathrm{PETCO}_{2}$ pour chacun des volatiles et ce, à $0.5 \mathrm{MAC}\left(r^{2}=0.99\right.$ et 0.99$)(P<0.05)$ ainsi $q u^{\prime} \dot{a} 1.0$ $M A C\left(r^{2}=0.96\right.$ et 0.95$)(P<0.05)$ respectivement. La CBFV pour l'isoflurane à 0.5 MAC et 1.0 MAC a augmentée significativement lorsque la $\mathrm{PETCO}_{2}$ augmentait de 20 à $60 \mathrm{mmHg}(P<0.05)$. La CBFV pour l' halothane à $0.5 \mathrm{MAC}$ et 1.0 MAC augmentait significativement seulement lorsque la $\mathrm{PETCO}_{2}$ passait de 20 à $40 \mathrm{mmHg}(P<0.05)$ pendant aucune 
augmentation supplémentaire était notée lorsque la $\mathrm{PETCO}_{2}$ passait de 40 à $60 \mathrm{mmHg}$. La RI+ a montré pour chacun des agents utilisés une relation logarithmique inverse à celle de la CBFV en fonction de la $\mathrm{PETCO}_{2}$ à $0.5 \mathrm{MAC}\left(r^{2}=0.98\right.$ et 0.99$)$ $(P<0.05)$ et $1.0 \mathrm{MAC}\left(r^{2}=0.76\right.$ et 0.53$)(P<0.05)$ respectivement. La CBFV n'a pas différée signicativement pour l' isoflurane ou l'halothane à $0.5 \mathrm{MAC}$ ou $1.0 \mathrm{MAC}$ et ce, à chaque niveau $\mathrm{PETCO}_{2}$ étudiées. La réponse cérébrovasculaire observée à $20 \mathrm{mmHg} \mathrm{PETCO}$ entre l' halothane $0.5 \mathrm{MAC}$ et 1.0 MAC n'était pas statistiquement significative $(P=0.056)$. Ces résultats indiques que l'isoflurane et l'halothane en concentration inspirées jusqu'à 1.0 MAC n'affecte pas la réacivité cérébrovasculaire de la MCA au $\mathrm{CO}_{2}$ chez des enfants sains et anesthésiés.

Transcranial Doppler sonography (TCD) is a noninvasive technique that measures the velocity of blood flowing in the large basal cerebral arteries. ${ }^{1-3}$ Hitherto, intracranial vessels were inaccessible to Doppler-shifted ultrasound measurements except in neonates and young infants. However, recently developed physical modifications have enabled measurement of middle cerebral artery (MCA) flow velocity through the temporal bone in anaesthetized children. ${ }^{2}$

Several factors affect cerebral blood flow (CBF) during anaesthesia including the carbon dioxide $\left(\mathrm{CO}_{2}\right)$ tension and the presence of volatile anaesthetics. Carbon dioxide directly affects the cerebral circulation by dilating the cerebral vessels and increasing cerebral blood flow. ${ }^{2,14}$ Carbon dioxide rapidly equilibrates across biological membranes and alters the perivascular $\mathrm{pH}$. Since the perivascular $\mathrm{pH}$ is an important determinant of cerebrovascular reactivity, $\mathrm{CO}_{2}$ exerts a rapid and considerable effect on CBF. ${ }^{3}$ Indeed, CBF varies directly and linearly with the $\mathrm{PaCO}_{2}$ between $\mathrm{CO}_{2}$ partial pressures of 20-60 $\mathrm{mmHg}$, in adults, while Pilato et al. showed a logarithmic relationship between $\mathrm{CBFV}$ and $\mathrm{PaCO}_{2}$ over the same range. ${ }^{2,3}$

Halothane is an excellent anaesthetic agent for children and is thus widely used in clinical paediatric practice. It is commonly used in combination with hyperventilation in paediatric neuroanaesthesia. A recent TCD study demonstrated a hysteresis phenomenon in children anaesthetized with up to $1.5 \mathrm{MAC}$ halothane. ${ }^{4}$ This finding could be important in patients with raised intracranial pressure. In animal studies halothane has been shown to decrease cerebrovascular resistance, increase cerebral blood flow and increase intracerebral pressure. ${ }^{5}$ Many human studies have supported these findings. ${ }^{6-9}$ Drummond et al. reported that the presence of hypocapnia resulted in a smaller reduction in cerebral blood flow (CBF) during the administration of halothane- $\mathrm{N}_{2} \mathrm{O}$ than with isoflurane-
$\mathrm{N}_{2} \mathrm{O} \cdot{ }^{10}$ Madsen et al. suggested that if thiopentone is used for induction and hypocapnia is established before the administration of 1.0 MAC halothane, cerebrovascular reactivity to a low $\mathrm{PaCO}_{2}$ is maintained. ${ }^{5}$ If hypocapnia is not established initially, halothane is believed to have the propensity to attenuate the cerebrovascular vasoconstrictive effect of a low $\mathrm{PaCO}_{2}$. ${ }^{9-11}$.

Isoflurane is considered to be the inhalational agent of choice in neuroanaesthesia because it dilates the cerebral vasculature to a lesser extent than halothane. We have demonstrated that the cerebral blood flow velocity (CBFV) and cerebrovascular resistance index (RI+) are constant during the administration of varying concentrations of isoflurane administered in a loop fashion to normocapnic children. ${ }^{12}$ Similar results were obtained in adult studies in which isoflurane concentrations up to 1 MAC had a minimal effect on CBF. ${ }^{13}$

In this paper the effects of $\mathrm{CO}_{2}$ between 20 and 60 $\mathrm{mmHg}$ on the CBFV and $\mathrm{RI}+$ in healthy children anaesthetised with either isoflurane or halothane at 0.5 MAC and 1.0 MAC concentrations are reported.

\section{Methods}

\section{Practical procedure}

Following approval from the Human Subjects Review Committee, written and informed consent was obtained from the parents of 30 healthy ASA physical status I or II children aged one to six years old scheduled for elective urological surgery. All children were fasting and unpremedicated. Patients with cardiac or neurological disease or patients with a contraindication to regional anaesthesia were excluded. All patients were supine and horizontal throughout the study.

After application of the usual monitoring, anaesthesia was induced with intravenous thiopentone $5 \mathrm{mg} \cdot \mathrm{kg}^{-1}$, fentanyl $2 \mu \mathrm{g} \cdot \mathrm{kg}^{-1}$, and vecuronium $0.1 \mathrm{mg} \cdot \mathrm{kg}^{-1}$. After tracheal intubation, intermittent positive pressure ventilation was established with peak inspiratory pressures maintained at $20-25 \mathrm{mmHg}$ and positive end-expiratory pressure at zero. Ventilation was adjusted to achieve a $\mathrm{PETCO}_{2}$ of $20 \mathrm{mmHg}$. A constant fresh gas flow was maintained throughout the study to avoid any changes in intrathoracic pressure. Anaesthesia was maintained with isoflurane or halothane in a mixture of air and oxygen to produce an $\mathrm{FiO}_{2}$ of 0.3 . Vecuronium $0.05 \mathrm{mg} \cdot \mathrm{kg}^{-1}$ was used for muscle relaxation. A continuous caudal or lumbar epidural block using $0.25 \%$ bupivacaine without epinephrine was administered to all patients before the surgical incision.

Normothermia was maintained using a heat and moisture exchanger (Gibeck-Dryden Corporation, Indianapolis, Indiana, USA) and a warming blanket. ${ }^{15-17}$ Lactated 
Ringer's solution $\left(5 \mathrm{ml} \cdot \mathrm{kg}^{-1}\right)$ was administered over the initial $15 \mathrm{~min}$ to replace the fluid deficit due to the fasting period. All patients received $2 \mathrm{ml} \cdot \mathrm{kg}^{-1} \cdot \mathrm{hr}^{-1}$ lactated Ringer's solution as maintenance fluid and additional lactated Ringer's as needed to replace blood or surgical losses. The end-tidal concentrations of isoflurane, halothane and $\mathrm{CO}_{2}$ were measured from the distal end of the tracheal tube and analyzed with a calibrated PuritanBennett Datex 254 airway gas monitor (Datex Instrumentation Corporation, Helsinki, Finland). ${ }^{18}$ The gas monitor was calibrated using a reference gas mixture before each use.

The initial end-tidal concentration of isoflurane was randomized to either 0.5 MAC or 1.0 MAC. The concentration of halothane was set at $0.5 \mathrm{MAC}$ because of its hysteresis effects. ${ }^{4}$ Three measurements of CBFV and $\mathrm{RI}+$ were recorded at each $\mathrm{CO}_{2}$ and isoflurane or halothane MAC value. Following these measurements, patients were equilibrated to the other concentration of isoflurane or 1.0 MAC halothane. Once again, three measurements of $\mathrm{CBFV}$ and $\mathrm{RI}+$ were made at each $\mathrm{CO}_{2}$ and isoflurane or halothane MAC value.

Doppler measurements were recorded after $15 \mathrm{~min}$ of steady-state isoflurane or halothane concentration. The $\mathrm{PETCO}_{2}$ was then adjusted randomly to either 20,40 , or $60 \mathrm{mmHg}$ by titrating exogenous $\mathrm{CO}_{2}$ into the anaesthetic circuit. The end-tidal $\mathrm{CO}_{2}$ was held constant for five minutes, after which the anaesthetist who was unable to see the TCD screen, recorded three consecutive measurements of CBFV and RI+ in the MCA at one-minute intervals. Systolic arterial pressure, heart rate, arterial oxygen saturation, temperature, inspired $\mathrm{O}_{2}$ fraction and end-tidal isoflurane or end-tidal halothane concentrations were recorded simultaneously.

\section{Doppler instrumentation}

The TCD monitor (Transpect TCD Medasonics, Canada) used to determine CBFV and RI+ had the following characteristics: emitted ultrasonic frequency $-2 \mathrm{MHz}$; emitting area $-1.5 \mathrm{~cm}_{2}$; effective depth range $-25-120$ $\mathrm{mm}$; and emitted ultrasonic power $-100 \mathrm{~mW}$. The frequency spectra of the Doppler signals were displayed on a real time spectrum analyzer (Medasonics 1024S) which allowed clear aural and visual separation of flow for unambiguous interpretation of the CBFV waveform.

The range-gated pulsed $T C D$ probe was placed over the temporal window of the skull just cephalad to the zygomatic arch approximately $1-2 \mathrm{~cm}$ anterior to the tragus. The gate depth was set to $30-35 \mathrm{~mm}$, initially, depending on the size of the patient according to the recommendations of Gillard et al. ${ }^{19}$ The Doppler signal was optimized for clear and accurate determinations by adjusting the gate depth, angle of insonation, power, and dynamic range. Once positioned, the TCD probe was fixed in place with a modified Mayo Ether Screen that allowed for continuous measurements of CBFV and RI+ in the MCA without affecting either the location of the probe or the angle of insonation.

Three CBFV, RI+ and graphic displays of systolic and diastolic flow velocities were obtained during haemodynamic steady-state periods at each $\mathrm{PETCO}_{2}$ for both the isoflurane and halothane concentrations studied. The Doppler frequency spectrum was displayed on a frequency analyzer and analyzed by fast Fourier transformation. The outline or envelope of the spectra was used to determine the CBFV within the MCA by positioning the cursor consecutively on three individual frequency outlines and averaging them. Fourier analysis provided a precise analysis based on the first or second harmonic of the cardiac cycle. The pulsatility index (RI+) was calculated from the mean of three displayed waveforms. The cerebrovascular resistance $\mathrm{RI}+$ was calculated for each MCA velocity measurement according to the formula:

$\mathrm{FI}+=\left(\mathrm{f}_{\text {syst }}-\mathrm{f}_{\text {dias }}\right) / \mathrm{f}_{\text {syst }}$

where $f_{\text {syst }}$ is the maximum frequency at the peak systole, and $f_{\text {diast }}$ is the maximum frequency at end diastole, calculated for a selected complete cardiac cycle, as adapted from Pourcelot's index of resistance. ${ }^{20}$

\section{Statistical analysis}

The mean \pm standard deviation (SD) for age and weight were determined. The analysis of each TCD file was done by an investigator $(\mathrm{BB})$ who was unaware of the sequence and the anaesthetic agent at which each file was recorded. Based on a previous study ${ }^{10}$ we expected a difference between halothane and isoflurane in the hypocapnic patient. With 15 patients per group and an alpha value 0.05 the power to detect such a difference in the cerebrovascular reactivity with halothane versus isoflurane is 0.80 . The relationships between the $\mathrm{PETCO}_{2}$ and both the CBFV and RI+ were determined using a nonlinear regression analysis. The dependence of both TCD variables on the $\mathrm{PCO}_{2}$ was calculated using the coefficient of determination $\left(\mathrm{r}^{2}\right)$. Repeated measures analysis of variance and the Student Newman-Keuls test for multiple comparisons were used to determine within group (isoflurane or halothane) $\mathrm{PETCO}_{2}$ effects and differences in $\mathrm{CBFV}, \mathrm{RI}+$, heart rate, systolic arterial pressure, temperature and arterial oxygen saturation. The unpaired $t$ test was used for between group isoflurane and halothane comparisons at similar PETCO $\mathrm{P}_{2}$ levels. A $P<0.05$ was considered statistically significant. 
TABLE I Data summary (halothane)

\begin{tabular}{|c|c|c|c|c|c|c|c|c|c|c|c|}
\hline & \multicolumn{3}{|c|}{ Hypocapnia } & \multicolumn{3}{|c|}{ Normocapnia } & \multicolumn{3}{|c|}{ Hypercapnia } & \multicolumn{2}{|l|}{$P^{b}$} \\
\hline & $E T_{\text {hal }} 0.5$ & $E T_{\text {hal }} I .0$ & $P^{a}$ & $E T_{\text {hal }} 0.5$ & $E T_{\text {hal }} l .0$ & $P^{a}$ & $E T_{\text {hat }} 0.5$ & $E T_{\text {hal }} 1.0$ & $P^{a}$ & 0.5 & 1.0 \\
\hline HR (beats/min) & $91 \pm 25$ & $91 \pm 15$ & ns & $93 \pm 22$ & $88.5 \pm 20$ & ns & $94 \pm 18$ & $93 \pm 16$ & ns & ns & ns \\
\hline SABP (mmHg) & $79 \pm 11$ & $76 \pm 12$ & ns & $81 \pm 11$ & $78 \pm 14$ & ns & $81 \pm 10$ & $79 \pm 13$ & ns & ns & ns \\
\hline $\mathrm{ETCO}_{2}(\mathrm{mmHg})$ & $20 \pm 2$ & $21 \pm 2$ & ns & $40 \pm 3$ & $40 \pm 2$ & ns & $59 \pm 2$ & $60 \pm 3$ & ns & ns & ns \\
\hline $\mathrm{SaO}_{2}(\%)$ & $98 \pm 2$ & $99 \pm 3$ & ns & $99 \pm 2$ & $99 \pm 1$ & ns & $99 \pm 2$ & $98 \pm 2$ & ns & ns & ns \\
\hline $\mathrm{AP}\left(\mathrm{cmH}_{2} \mathrm{O}\right)$ & $21 \pm 3$ & $22 \pm 4$ & ns & $20 \pm 2$ & $19 \pm 4$ & ns & $21 \pm 4$ & $22 \pm 3$ & ns & ns & ns \\
\hline Temp $\left({ }^{\circ} \mathrm{C}\right)$ & $\begin{array}{l}36.5 \\
\pm 0.3\end{array}$ & $\begin{array}{l}36.7 \\
\pm 0.2\end{array}$ & ns & $\begin{array}{l}36.6 \\
\pm 0.2\end{array}$ & $\begin{array}{l}36.7 \\
\pm 0.2\end{array}$ & ns & $\begin{array}{l}36.5 \\
\pm 0.3\end{array}$ & $\begin{array}{l}36.6 \\
\pm 0.2\end{array}$ & ns & ns & ns \\
\hline $\mathrm{CBFV}\left(\mathrm{cmsec}^{-1}\right)$ & $\begin{array}{l}82.6 \\
\pm 30.6\end{array}$ & $\begin{array}{l}105.27 \\
\pm 32.29\end{array}$ & 0.056 & $\begin{array}{l}130.33 \\
\pm 37.8\end{array}$ & $\begin{array}{l}134.13 \\
\pm 33.54\end{array}$ & ns & $\begin{array}{l}140.0 \\
\pm 39.4\end{array}$ & $\begin{array}{l}143.47 \\
\pm 39.01\end{array}$ & ns & $<0.05^{*}$ & $<0.05 \dagger$ \\
\hline $\mathbf{R I +}$ & $\begin{array}{l}0.64 \\
\pm 0.06\end{array}$ & $\begin{array}{l}0.66 \\
\pm 0.09\end{array}$ & ns & $\begin{array}{l}0.63 \\
\pm 0.10\end{array}$ & $\begin{array}{l}0.61 \\
\pm 0.05\end{array}$ & ns & $\begin{array}{l}0.60 \\
\pm 0.10\end{array}$ & $\begin{array}{l}0.63 \\
\pm 0.08\end{array}$ & ns & ns & ns \\
\hline
\end{tabular}

All values are mean (SD), $n=15 /$ group.

Abbreviations: $\mathrm{ET}_{\text {hal }} 0.5$, end-tidal halothane 0.5 $\mathrm{MAC} \mathrm{ET}_{\text {hal }} 1.0$, end-tidal halothane $1.0 \mathrm{MAC} ; \mathrm{ET}_{\text {iso }} 0.5$, end-tidal isoflurane $0.5 \mathrm{MAC} \mathrm{ET}_{\text {iso }} 1.0$ $\mathrm{MAC}$, end-tidal isoflurane 1.0 MAC; HR, heart rate; $\mathrm{SABP}$, systolic arterial blood pressure; $\mathrm{SaO}_{2}$, arterial oxygen saturation; Temp, body temperature; AP, airway pressure; CBFV, cerebral blood flow velocity; RI+, cerebrovascular resistance.

${ }^{a} \mathrm{P}$ values obtained by unpaired $\mathrm{t}$ test between both $\mathrm{MAC}$ at comparable $\mathrm{ETCO}_{2}$.

${ }^{b} \mathrm{P}$ values are obtained by repeated-measures of variance and Student Newman-Keuls for multiple comparisons within each MAC for all three levels of $\mathrm{ETCO}_{2}$.

*Comparing $\mathrm{ET}_{\mathrm{hal}} 0.5 \mathrm{MAC}$ at $\mathrm{ETCO}_{2} 40$ with $20 \mathrm{mmHg}(P<0.01)$; 60 with $20 \mathrm{mmHg}(P<0.05) ; 60$ with $40 \mathrm{mmHg}(P=\mathrm{NS})$.

† Comparing $\mathrm{ET}_{\mathrm{hal}} 1.0 \mathrm{MAC}$ at $\mathrm{ETCO}_{2} 40$ with $20 \mathrm{mmHg}(P<0.001) ; 60$ with $20 \mathrm{mmHg}(P=0.001) ; 60$ with $40 \mathrm{mmHg}(P=\mathrm{NS})$.

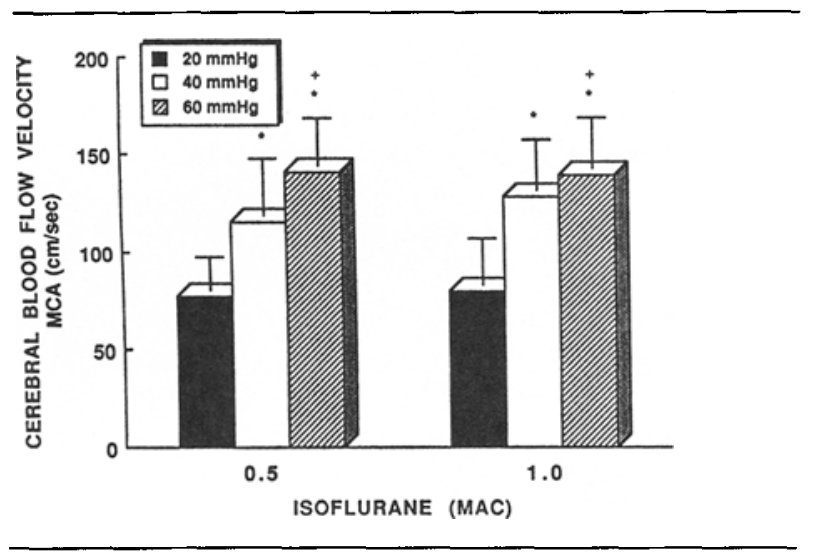

FIGURE 1 Cerebral blood flow velocity (CBFV) versus PETCO $_{2}$. $\mathrm{P}<0.05$ compared with $20 \mathrm{mmHg}^{*}$ and $40 \mathrm{mmHg}^{+}$.

\section{Results}

Age and weight did not differ between the isoflurane and halothane groups. The mean \pm SD ages and weights of the 15 children in each group were $39.4 \pm 27.2 \mathrm{mo}$ and $15.5 \pm 6.2 \mathrm{~kg}$ for isoflurane, and $41.7 \pm 27.9 \mathrm{mo}$ and $15.5 \pm 5.9 \mathrm{~kg}$ for halothane. Heart rate, systolic arterial blood pressure, $\mathrm{ETCO}_{2}$, arterial oxygen saturation, airway pressure, and temperature did not change between 0.5 and 1.0 MAC for halothane (Table I) and for isoflurane (Table II) during the study period. Doppler recordings of the CBFV in the $\mathrm{MCA}$ and calculations of $\mathrm{RI}+$ values were completed in all children at $0.5 \mathrm{MAC}$

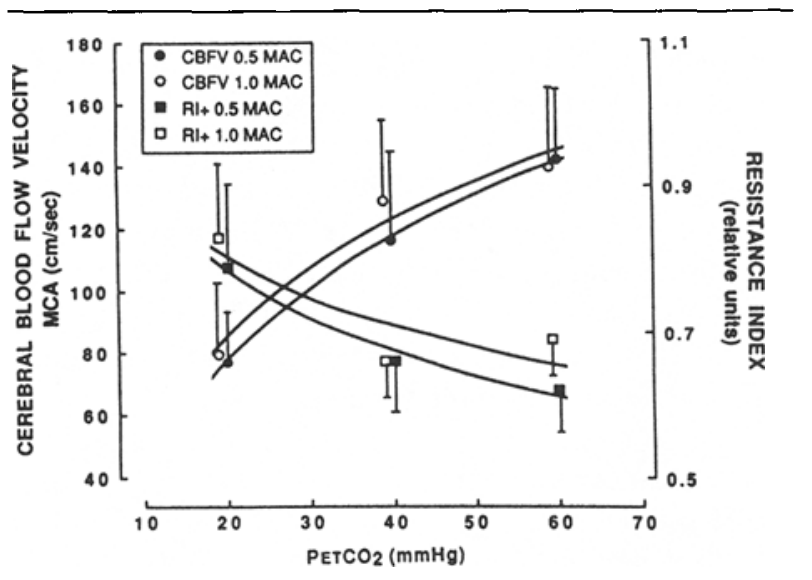

FIGURE 2 Cerebral blood flow velocity (CBFV) and cerebrovascular resistance index (RI+) for isoflurane versus $\mathrm{PETCO}_{2}$. Values are mean $\left( \pm \mathrm{SD}\right.$ ) for 15 subjects at each $\mathrm{PETCO}_{2}$ value. Lines represent the non-linear regression fits for the CBFV and RI+ versus $\mathrm{PETCO}_{2}$. The CBFV increased versus PETCO ${ }_{2}$ at $0.5 \mathrm{MAC}\left(r^{2}=0.99\right)$ and at 1.0 MAC $\left(r^{2}=0.96\right)$. The $R I+$ decreased versus $\mathrm{PETCO}_{2}$ at 0.5 $\operatorname{MAC}\left(r^{2}=0.98\right)$ and 1.0 MAC $\left(r^{2}=0.76\right)$.

and 1.0 MAC halothane (Table I) and isoflurane (Table II) at each of the three $\mathrm{PETCO}_{2}$ values.

We found that the CBFV increased significantly as $\mathrm{PETCO}_{2}$ increased from 20 to $40 \mathrm{mmHg}(P<0.001)$ and from 40 to $60 \mathrm{mmHg}(P<0.05)$ at $0.5 \mathrm{MAC}$ and from 20 to $40 \mathrm{mmHg}(P<0.001)$ and 40 to $60 \mathrm{mmHg}(P<0.05)$ at 1.0 MAC isoflurane (Figure 1). However, CBFV did 
TABLE II Data summary (isoflurane)

\begin{tabular}{|c|c|c|c|c|c|c|c|c|c|c|c|}
\hline & \multicolumn{3}{|c|}{ Hypocapnia } & \multicolumn{3}{|c|}{ Normocapnia } & \multicolumn{3}{|c|}{ Hypercapnia } & \multicolumn{2}{|l|}{$P^{b}$} \\
\hline & $E T_{i s o} 0.5$ & $E T_{i s o} 1.0$ & $P^{a}$ & $E T_{i s o} 0.5$ & $E T_{i s o} 1.0$ & $P^{a}$ & $E T_{i s o} 0.5$ & $E T_{i s o} 1.0$ & $P^{a}$ & 0.5 & 1.0 \\
\hline HR (beats/min) & $93 \pm 17$ & $95 \pm 14$ & ns & $100 \pm 14$ & $97 \pm 14$ & ns & $99 \pm 20$ & $93 \pm 13$ & ns & ns & ns \\
\hline SABP $(m m H g)$ & $84 \pm 10$ & $81 \pm 10$ & ns & $86 \pm 10$ & $82 \pm 9$ & ns & $89 \pm 11$ & $85 \pm 10$ & ns & ns & ns \\
\hline $\mathrm{ETCO}_{2}(\mathrm{mmHg})$ & $21 \pm 2$ & $21 \pm 3$ & ns & $39 \pm 3$ & $40 \pm 2$ & ns & $60 \pm 2$ & $61 \pm 2$ & ns & ns & ns \\
\hline $\mathrm{SaO}_{2}(\%)$ & $99 \pm 2$ & $99 \pm 3$ & ns & $99 \pm 2$ & $98 \pm 3$ & ns & $97 \pm 3$ & $98 \pm 2$ & ns & ns & ns \\
\hline $\mathrm{AP}\left(\mathrm{cmH}_{2} \mathrm{O}\right)$ & $22 \pm 3$ & $22 \pm 4$ & ns & $20 \pm 2$ & $21 \pm 4$ & ns & $22 \pm 4$ & $22 \pm 3$ & ns & ns & ns \\
\hline Temp $\left({ }^{\circ} \mathrm{C}\right)$ & $\begin{array}{l}36.6 \\
\pm 0.2\end{array}$ & $\begin{array}{l}36 \\
\pm 0.2\end{array}$ & ns & $\begin{array}{l}36.6 \\
\pm 0.2\end{array}$ & $\begin{array}{l}36.4 \\
\pm 0.3\end{array}$ & ns & $\begin{array}{l}36.7 \\
\pm 0.3\end{array}$ & $\begin{array}{l}36.6 \\
\pm 0.2\end{array}$ & ns & ns & ns \\
\hline $\mathrm{CBFV}\left(\mathrm{cmsec}^{-1}\right)$ & $\begin{array}{l}76.6 \\
\pm 17.5\end{array}$ & $\begin{array}{l}79.82 \\
\pm 20.93\end{array}$ & $\mathrm{~ns}$ & $\begin{array}{l}115.64 \\
\pm 28.69\end{array}$ & $\begin{array}{l}121.28 \\
\pm 20.93\end{array}$ & ns & $\begin{array}{l}141.1 \\
\pm 23.36\end{array}$ & $\begin{array}{l}139.03 \\
\pm 22.02\end{array}$ & ns & $<0.05^{*}$ & $<0.05 \dagger$ \\
\hline RI+ & $\begin{array}{l}0.79 \\
\pm 0.11\end{array}$ & $\begin{array}{l}0.83 \\
\pm 0.1\end{array}$ & ns & $\begin{array}{l}0.66 \\
\pm 0.07\end{array}$ & $\begin{array}{l}0.66 \\
\pm 0.05\end{array}$ & ns & $\begin{array}{c}0.62 \\
\pm 0.06\end{array}$ & $\begin{array}{l}0.69 \\
\pm 0.05\end{array}$ & ns & $\mathrm{ns}$ & ns \\
\hline
\end{tabular}

All values are mean (SD), $n=15 /$ group.

Abbreviations: $\mathrm{ET}_{\text {hal }} 0.5$, end-tidal halothane $0.5 \mathrm{MAC} ; \mathrm{ET}_{\text {hal }} 1.0$, end-tidal halothane $1.0 \mathrm{MAC} ; \mathrm{ET}_{\text {iso }} 0.5$, end-tidal isoflurane $0.5 \mathrm{MAC} \mathrm{ET}_{\text {iso }} 1.0$ $\mathrm{MAC}$, end-tidal isoflurane 1.0 MAC; $\mathrm{HR}$, heart rate; $\mathrm{SABP}$, systolic arterial blood pressure; $\mathrm{SaO}_{2}$, arterial oxygen saturation; Temp, body temperature; $\mathrm{AP}$, airway pressure; $\mathrm{CBFV}$, cerebral blood flow velocity; $\mathrm{RI}+$, cerebrovascular resistance.

${ }^{a} \mathrm{P}$ values obtained by unpaired $\mathrm{t}$ test between both $\mathrm{MAC}$ at comparable $\mathrm{ETCO}_{2}$.

${ }^{b} \mathrm{P}$ values are obtained by repeated-measures of variance and Student Newman-Keuls for multiple comparisons within each MAC for all three levels of $\mathrm{ETCO}_{2}$.

*Comparing $\mathrm{ET}_{\mathrm{ha} 1} 0.5 \mathrm{MAC}$ at $\mathrm{ETCO}_{2} 40$ with $20 \mathrm{mmHg}(P<0.01) ; 60$ with $20 \mathrm{mmHg}(P<0.05) ; 60$ with $40 \mathrm{mmHg}(P=\mathrm{NS})$.

†Comparing $\mathrm{ET}_{\text {hal }} 1.0 \mathrm{MAC}$ at $\mathrm{ETCO}_{2} 40$ with $20 \mathrm{mmHg}(P<0.001) ; 60$ with $20 \mathrm{mmHg}(P=0.001) ; 60$ with $40 \mathrm{mmHg}(P=\mathrm{NS})$.

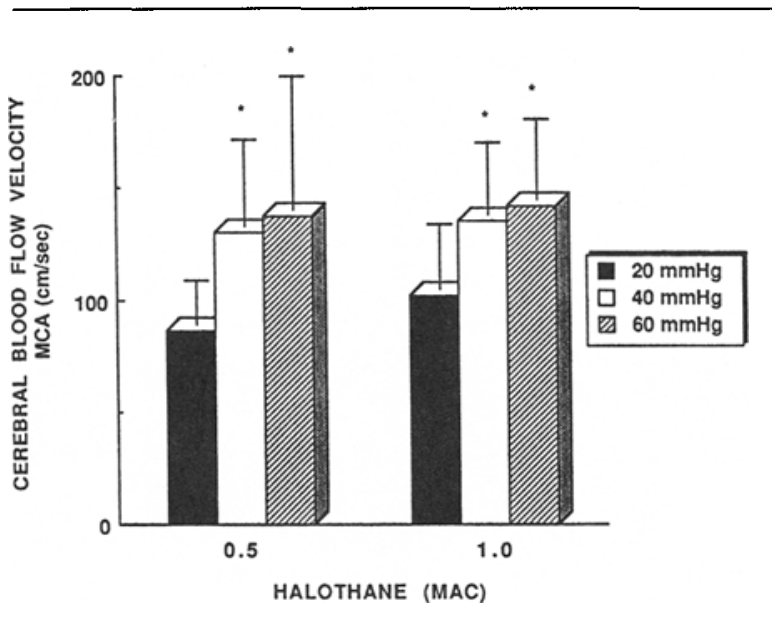

FIGURE 3 Cerebral blood flow velocity (CBFV) versus $\mathrm{PETCO}_{2}$ $P<0.05$ compared with $20 \mathrm{mmHg}^{*}$ and $40 \mathrm{mmHg}^{+}$.

not differ significantly between $0.5 \mathrm{MAC}$ and 1.0 MAC isoflurane at corresponding PETCO, values. The CBFV increased as PETCO $_{2}$ increased during both $0.5 \mathrm{MAC}$ $\left(\mathrm{r}^{2}=0.99\right)$ and 1.0 MAC $\left(\mathrm{r}^{2}=0.96\right)$ isoflurane $(P<$ 0.05 ). The RI+ showed the reverse relationship observed with $\mathrm{CBFV}$ when $\mathrm{PETCO}_{2}$ increased at both $0.5 \mathrm{MAC}\left(\mathrm{r}^{2}\right.$ $=0.98)$ and $1.0 \mathrm{MAC}\left(\mathrm{r}^{2}=0.76\right)$ isoflurane $(P<0.05)$ (Figure 2).

The CBFV increased significantly as $\mathrm{PETCO}_{2}$ increased from 20 to $40 \mathrm{mmHg}(P=0.007)$ at $0.5 \mathrm{MAC}$ and

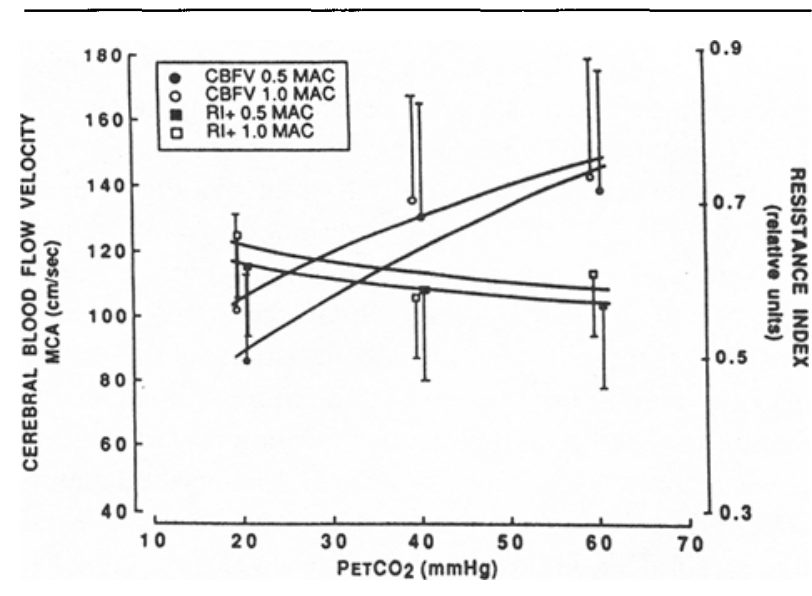

FIGURE 4 Cerebral blood flow velocity (CBFV) and cerebrovascular resistance index (RI+) for halothane versus $\mathrm{PETCO}_{2}$. Values are mean ( \pm SD) for 15 subjects at each PETCO $_{2}$ values. Lines represent the non-linear regression fits for the $\mathrm{CBFV}$ and $\mathrm{RI}+$ versus $\mathrm{PeTCO}_{2}$. The CBFV increased versus $\mathrm{PeTCO}_{2}$ at $0.5 \mathrm{MAC}\left(\mathrm{r}^{2}=0.99\right)$ and at 1.0 MAC $\left(r^{2}=0.95\right)$. The $\mathrm{RI}+$ decreased versus $\mathrm{PETCO}_{2}$ at $0.5 \mathrm{MAC}\left(r^{2}=0.99\right)$ and 1.0 MAC $\left(r^{2}=0.53\right)$.

from 20 to $40 \mathrm{mmHg}(P<0.001)$ at $1.0 \mathrm{MAC}$ halothane $(P<0.05)$, but did not change as $\mathrm{PETCO}_{2}$ increased from 40 to $60 \mathrm{mmHg}$ for both $0.5 \mathrm{MAC}$ and $1.0 \mathrm{MAC}$ halothane (Figure 3). The CBFV did not differ between 0.5 MAC and 1.0 MAC halothane at the three $\mathrm{PETCO}_{2}$ values. The $\mathrm{CBFV}$ increased as $\mathrm{PETCO}_{2}$ increased during 
both 0.5 MAC $\left(\mathrm{r}^{2}=0.99\right)$ and 1.0 MAC $\left(\mathrm{r}^{2}=0.95\right)$ halothane $(P<0.05)$. The $\mathrm{RI}+$ decreased as $\mathrm{PETCO}_{2}$ increased at both $0.5 \mathrm{MAC}\left(\mathrm{r}^{2}=0.99\right)$ and 1.0 MAC $\left(\mathrm{r}^{2}\right.$ $=0.53)$ halothane $(P<0.05)$ (Figure 4$)$.

There were no complications from the use of the TCD in this study.

\section{Discussion}

The results of this investigation strongly suggest that isoflurane and halothane in doses up to 1.0 MAC do not affect the cerebrovascular reactivity of the $\mathrm{MCA}$ to $\mathrm{CO}_{2}$ in anaesthetized, healthy children. Earlier investigations in animals and in adult humans produced contradictory results with regard to the effect of $\mathrm{CO}_{2}$ on the cerebrovasculature especially during halothane anaesthesia ${ }^{6-9}$ However, studies on cerebrovascular reactivity to $\mathrm{CO}_{2}$, during isoflurane anaesthesia were consistent. ${ }^{9-10}$

The results of the present study failed to show an adverse effect of halothane (0.5 MAC or 1.0 MAC) on cerebrovascular reactivity to $\mathrm{CO}_{2}$ when different $\mathrm{CO}_{2}$ concentrations were introduced after halothane. Wollman et al. ${ }^{6}$ reported that during halothane anaesthesia, arterial $\mathrm{PCO}_{2}$ levels affect cerebrovascular resistance and CBF in the same manner as in the non-anaesthetised man. Their findings are similar to ours for patients with normocapnia and hypocapnia. However, they did not study the magnitude of the vasoconstrictive response to hypocapnia. ${ }^{6}$ This present study shows that the cerebrovascular response between 0.5 MAC and 1.0 MAC halothane, even at $20 \mathrm{mmHg} \mathrm{PeTCO}_{2}$, was preserved. Many recent studies have suggested that halothane produces cerebral vasodilatation either by intracellular alteration of cyclicAMP ${ }^{21}$ decreased calcium accumulation in the sarcoplasmic reticulum, ${ }^{22}$ or by interacting with an endothelium-derived relaxing factor. ${ }^{23}$ Manohar et al. reported that during halothane- $\mathrm{O}_{2}$ anaesthesia, vasodilatation occurred in all regions of the brain. ${ }^{24}$ Their study showed that cerebral blood flow increased from values obtained at 0.5 MAC halothane to reach a maximum at 1.5 MAC halothane whereas the cerebral vascular resistance decreased to its lowest value at $1.0 \mathrm{MAC}$ halothane. ${ }^{24} \mathrm{We}$ have observed that between normocapnia and hypercapnia either at $0.5 \mathrm{MAC}$ or at 1.0 MAC halothane concentrations no additional vasodilatation was caused by increasing the level of $\mathrm{CO}_{2}$. This may suggest that halothane causes a maximal degree of cerebral vasodilatation and that subsequent increases in $\mathrm{PaCO}_{2}$ do not increase vasodilatation. Lazzell et al. using a similar anaesthetic technique reported that at normocapnia CBFV and $\mathrm{RI}+$ changed between $0.5 \mathrm{MAC}$ and 1.0 MAC but they failed to show any further changes at $1.5 \mathrm{MAC}^{25}$ They also observed that in spite of decreasing the halothane concentration from 1.5 MAC to $0.2 \mathrm{MAC}$, an increased cerebral blood flow velocity was maintained for approximately $30-45 \mathrm{~min}^{4}$ - an hysteresis phenomenon. Based on their observations we did not randomize the halothane concentrations. Our results suggest that halothane has as potent a vasodilating effect as $\mathrm{CO}_{2}$.

Cerebrovascular reactivity to hypocapnia has been shown to be more pronounced during isoflurane than during halothane anaesthesia in animals. ${ }^{10}$ The results reported in this paper are in agreement with the previously observed effects of isoflurane on CBF and cerebrovascular responses to $\mathrm{CO}_{2}$ obtained in dogs ${ }^{10,26}$ and in adults anaesthetized with isoflurane. ${ }^{27}$ It was interesting to observe with isoflurane that, between each level of $\mathrm{CO}_{2}$ studied, a statistical difference in CBFV was measured. Pilato et al. demonstrated, at $1 \%$ end-tidal isoflurane, a logarithmic relationship between $20 \mathrm{mmHg}$ and 60 mmHg $\mathrm{PeTCO}_{2}$ and the CBFV of the MCA. ${ }^{2}$ This suggests that the cerebrovascular dilatation observed in this study is related principally to the effect of $\mathrm{CO}_{2}$ and not to the variation in isoflurane concentrations. In addition, Leon $e t$ al. showed that during normocapnia, varying the concentration of isoflurane between 0.5 MAC and 1.0 MAC in a loop fashion, did not change CBFV of the MCA. ${ }^{12}$ They were unable to show any time-response effect of 1.0 MAC of isoflurane on CBFV of the MCA in anaesthetized children over $90 \mathrm{~min}$. These results are similar to those of Algotsson et al. and Eintrei et al. at similar concentrations of isoflurane in adults. ${ }^{27,28}$

Arterial $\mathrm{PCO}_{2}$ was estimated by measuring the endtidal $\mathrm{CO}_{2}$ at the tip of the tracheal tube. Previous studies have shown that both single-breath and continuous distal PeTCO $\mathrm{C}_{2}$ closely approximates $\mathrm{PaCO}_{2}$ in healthy infants and children. ${ }^{18,29}$ The time constant for the equilibration of alveolar and arterial $\mathrm{CO}_{2}$ is one minute. ${ }^{30}$ We waited for five minutes at each $\mathrm{CO}_{2}$ tension to ensure complete cerebral arteriolar response to $\mathrm{CO}_{2}$. The equilibration time constant in cerebral grey matter for isoflurane and halothane is 1.4 and $2.4 \mathrm{~min}$, respectively. ${ }^{31}$ We waited for $15 \mathrm{~min}$ to achieve steady-state conditions within the brain. The data showed no consistent changes between the first and third measurements at each concentration. It was concluded that the equilibration periods used for $\mathrm{CO}_{2}$, isoflurane, and halothane produced steady-state conditions within the basal cerebral arteries.

The cerebrovascular response to $\mathrm{PCO}_{2}$ has been shown to depend in part on the arterial blood pressure. ${ }^{32,33}$ Neither heart rate nor systolic arterial pressure changed at any time during the study. If the systolic arterial pressure had decreased as the concenration of isoflurane or halothane was increased then CBFV would have decreased providing that the arterial diameter remained unchanged. However, we found that CBFV did not change between 0.5 MAC and 1.0 MAC isoflurane. An 
electrical model of the systemic arterial system has been used to demonstrate that the CBFV and resistance index $\mathrm{RI}+$ is likely to be affected by changes in heart rate and arterial blood pressure. ${ }^{34}$ Since systolic arterial pressure and heart rate did not change we believe that the changes observed in CBFV and RI+ were due to $\mathrm{PCO}_{2}$.

Intrathoracic pressure alters the cerebral perfusion pressure by a direct effect on the cerebral venous pressure. A constant mean intrathoracic pressure was maintained during each study to isolate the effect of changes in ventilation on CBFV. The $\mathrm{PETCO}_{2}$ was adjusted from an initial $\mathrm{PETCO}_{2}$ of $20 \mathrm{mmHg}$ produced by hyperventilation by the addition of exogenous $\mathrm{CO}_{2}$ without altering the ventilator settings. Thus, the observed changes in CBFV at different $\mathrm{PETCO}_{2}$ values could not be attributed to changes in intrathoracic pressure and/or venous return.

Interindividual variability could introduce error in the measurements. Each individual has a unique CBFV (an estimate of CBF) and this is determined by many factors such as metabolic demand, physiological state, blood pressure, blood properties and pathologic state. In fact, age is the major determinant of the CBFV. There is a linear increase in CBFV from birth to age two months. Thereafter it increases more slowly to reach a peak at six years old and then decreases slowly to $70 \%$ of this peak value at the age of 16 . The CBFV then decreases an additional $20 \%$ between 20 and 60 yr of age. ${ }^{35,36}$

Patients in this study all had similar haemoglobin concentrations $\left(12-14 \mathrm{mg} \cdot \mathrm{dl}^{-1}\right)$, metabolic demands (normothermia was maintained), and haemodynamic profiles (no change in blood pressure or heart rate at any time). The large standard deviations seen could therefore be explained by the range of ages of patients studied in this series (1-8 yr).

There are several methodological considerations that merit comment. The cerebral blood flow (CBF) and cerebrovascular resistance were measured by transcranial Doppler and several assumptions underly the relationship between CBFV and CBF. Four assumptions have to be made in regard to the TCD methodology before recording the CBFV in the MCA. They have been previously described. ${ }^{2}$ Other potential pitfalls in measurements which could account for large standard deviations include errors based on the physics of sound waves and Doppler instruments. These include (a) an inability to separate adjacent vessels high pass filters designed to cut off low frequencies, noise or signals from wall motion, inadequate sampling frequency, (b) quality and adjustment of the Doppler equipment (problems due to low sensitivity to weak signals, absence of adequate filtering and insufficient precision of alignment), (c) an inadequate examination technique (operator error, large angle of insonation), anatomy of the brain vasculature, blood rheology (low viscosity gives high CBFV), and interpretation of Doppler spectra. ${ }^{37}$ All mentioned pitfalls may be avoided by an experienced examiner and are believed to be of little importance. The changes in TCD blood flow velocity reflect concomitant changes in CBF. Studies in humans and animals show a close correlation between changes in TCD velocity and $\mathrm{CBF}$ both in response to $\mathrm{CO}_{2}$ and following treatment with anaesthetics and narcotics. ${ }^{38}$ Several TCD studies have suggested that changes in velocity are proportional to changes in flow. ${ }^{39-41}$ However, absolute CBF values cannot be inferred from TCD data since the diameter of the insonated vessel segment remains unknown. Giller et al ${ }^{42}$ reported the calibre of the large cerebral arteries in adult humans undergoing craniotomy does not change during variations in blood pressure and $\mathrm{PCO}_{2}$. They showed that the calibre of the proximal cerebral arteries does not change but the small arterial branches may change diameter during pressure changes. Although the major part of cerebral vascular regulation occurs on the level of the resistance vessels, ${ }^{43}$ further paediatric investigations involving classical CBF measurements and TCD are necessary to determine if intracranial vessel diameter changes. Until then, interpretation of TCD data in terms of absolute CBF should be made cautiously. However, TCD offers a continuous and non-invasive recording system with the ability to measure the trend in inadequate CBF reliably. Transcranial Doppler measurements have been used with success during carotid endarterectomy to detect perfusion changes following cross-clamping of the internal carotid. Padayachee et al. ${ }^{44}$ have shown a significant decrease in MCA blood flow velocity during temporary occlusion of the internal carotid. Halsey et al. ${ }^{45}$ showed that cortical CBF and CBFV correlated closely when CBF was low but not when CBF was high. Detection of emboli and inadequate blood flow during surgery are other indications. Albin et $a l .{ }^{46}$ detected high frequency signals that were related to air embolism. The TCD has allowed us to suggest that during hypothermic low-flow cardiopulmonary bypass CBF was not always assured. ${ }^{47}$ Cerebral circulatory arrest related to decrease in intracranial compliance such as brain-dead subjects is associated with biphasic signal of low amplitude and a progressive reduction in the diastolic Doppler signal. ${ }^{48}$

In summary, the results of this study indicate that in healthy children anaesthetized with $0.5 \mathrm{MAC}$ or $1.0 \mathrm{MAC}$ halothane or isoflurane, the responsiveness of the cerebral circulation to carbon dioxide measured by TCD on the MCA is preserved when the $\mathrm{PETCO}_{2}$ is increased from 20 $\mathrm{mmHg}$ to $60 \mathrm{mmHg}$. Cerebrovascular reactivity to $\mathrm{CO}_{2}$ may also be preserved with both volatile anaesthetic agents studied. However, the least intrinsic vasodilatory effect was observed with isoflurane. This may be of 
possible benefit in neuroanaesthesia in the clinical concentrations studied compared with halothane. Further investigations are required to determine the possible effects of cerebrovascular reactivity to $\mathrm{CO}_{2}$ at higher MAC multiples of isoflurane and halothane.

\section{Acknowledgements}

We thank Medasonics Incorporated, Canada for providing the Transpect Transcranial Doppler instrument to undertake this study. We also thank Drs. B. Churchill, G. McLorie, T. Khoury, the Fellows, Residents and the Nurses of the Department of Urology for their patience and cooperation during this study. We are grateful to Dr. J.E.S. Relton for taking the time to review and help in the careful preparation of this manuscript.

\section{References}

1 Aaslid R, Markwalder TM, Nornes $H$. Noninvasive transcranial Doppler ultrasound recording of flow velocity in basal cerebral arteries. J Neurosurg 1982; 57: 769-74.

2 Pilato MA, Bissonnette B, Lerman J. Cranial Duplex sonography: effect of $\mathrm{PCO}_{2}$ on the velocity of blood in the cerebral vasculature of anaesthetized children. Can J Anaesth 1989; 36: S89.

3 Markwalder TM, Grolimund P, Seller RW, Roth F, Aaslid $\boldsymbol{R}$. Dependency of blood flow velocity in the middle cerebral artery on end-tidal carbon dioxide partial pressure - a transcranial ultrasound Doppler study. J Cereb Blood Flow Metab 1984; 4: 368-72.

4 Lazzell V, Bissonnette B, Lerman J. Effect of halothane on the cerebral circulation in infants and children: a hysteresis phenomenon. Anesthesiology 1989; 71: A327.

5 Madsen JB, Cold GE, Hansen ES, Bardrum B. Cerebral blood flow, cerebral metabolic rate of oxygen and relative $\mathrm{CO}_{2}$-reactivity during craniotomy for supratentorial cerebral tumours in halothane anaesthesia. A doseresponse study. Acta Anaesthesiol Scand 1987; 31: 151-7.

6 Wollman H, Alexander SC, Cohen PJ, Chase PE, Melman $E$, Behar $M G$. Cerebral circulation of man during halothane anesthesia: effects of hypocardia and of d-tubocurarine. Anesthesiology 1964; 25: 180-4.

7 Christensen MS, Hoerdt-Rasmussen K, Lassen NA. Cerebral vasodilatation by halothane anaesthesia in man and its potentiation by hypotension and hypercapnia. $\mathrm{Br} \mathrm{J}$ Anaesth 1967; 39: 927-34.

8 Jennett WB, McDowall DG, Barker J. The effect of halothane on intracranial pressure in cerebral tumors. $\mathbf{J}$ Neurosurg 1967; 26: 270-4.

9 Adams RW, Gronert GA, Sundi TM, Michenfelder JD. Halothane, hypocapnia and cerebrospinal fluid pressure in neurosurgery. Anesthesiology 1972; 37: 510- 7 .
10 Drummond JC, Todd MM. The response of the feline cerebral circulation to $\mathrm{PaCO}_{2}$ during anesthesia with isoflurane and halothane and during sedation with nitrous oxide. Anesthesiology 1985; 62: 268-73.

11 McDowall DG, Barker J, Jennett WB. Cerebrospinal fluid pressure measurements during anaesthesia. Anaesthesia 1966; 21: 189-201.

12 Leon JE, Bissonnette B. Does cerebrovascular hysteresis exist under isoflurane anesthesia in children? Anesth Analg 1991; 72: S160.

13 Shapiro HM. Anesthesia Effects Upon Cerebral Blood Flow, Cerebral Metabolism, and the Electroencephalogram. In: Miller RD (Ed.). Anesthesia, 2nd ed., New York: Churchill Livingstone Inc., 1986: 1265-6.

14 Shapiro HM. Anaesthesia Effects upon Cerebral Blood Flow, Cerebral Metabolism, and the Electroencephalogram. In: Miller RD (Ed.). Anesthesia, 2nd ed., New York: Churchill Livingstone Inc., 1986: 795-824.

15 Bissonnette $B$, Sessler DI. Passive or active inspired gas humidification increases thermal steady-state temperatures in anesthetised infants. Anesth Analg 1989; 69: 783-7.

16 Bissonnette B, Sessler DI, LaFlamme P. Temperature monitoring sites in infants and children. Anesth Analg 1989; 69: 192-6.

17 Bissonnette B, Sessler DI, LaFlamme P. Passive and active inspired gas humidification in infants and children. Anesthesiology 1989; 71: 381-4.

18 Badgwell JM, McLeod ME, Lerman J, Creighton RE. End-tidal $\mathrm{PCO}_{2}$ measurements sampled at the distal and proximal ends of the endotracheal tube in infants and children. Anesth Analg 1987; 66: 950-64.

19 Gillard JH, Kirkham FJ, Levin SD, Neville BGR, Gosling $R G$. Anatomical validation of middle cerebral artery position as identified by transcranial Doppler ultrasound. J Neurol Neurosurg Psychiatry 1986; 49: 1025-9.

20 Pourcelot $L$. Present and Future of Diagnosic Ultrasound. In: Donald I, Leve S (Eds.). Diagnostic Ultrasound for Cerebral Vascular Disease. Rotterdam: Kooker Scientific Publication, 1976: 141-7.

21 MacMurdo SD, Nemoto EM, Nikki P, Frankenberry $M J$. Brain cyclic-AMP and possible mechanisms of cerebrovascular dilation by anesthetics in rats. Anesthesiology $55 ; 4$ : 435-8.

$22 \mathrm{Su} J Y$, Zhang CC. Intracellular mechanisms of halothane's effect on isolated aortic strips of the rabbit. Anesthesiology 71; 3: 409-17.

23 Muldoon SM, Hart JL, Bowen KA, Freas $W$. Attenuation of endothelium-mediated vasodilation by halothane. Anesthesiology 68; 1: 31-7.

24 Manohar M, Goetz TL. Cerebral, renal, adrenal, intestinal and pancreatic circulation in conscious ponies and 
during 1.0,1.5, and 2.0 minimal alveolar concentrations of halothane- $\mathrm{O}_{2}$ anesthesia. Am J Vet Res 46; 12: 2492-7.

25 Lazzell V, Bissonnette B, Pilato MA, Lerman J. Transcranial Doppler sonography: effect of halothane on cerebral hemodynamics in children. Anesthesiology 1989; 71 : A322.

26 McPherson $R W$, Brian JE, Traystman RJ. Cerebrovascular responsiveness to carbon dioxide in dogs with $1.4 \%$ and $2.8 \%$ isoflurane. Anesthesiology 1989; 70: 843-50.

27 Algotsson L, Messeter K, Nordstrom CH, Ryding E. Cerebral blood flow and oxygen consumption during isoflurane and halothane anaesthesia in man. Acta Anaesthesiol Scand 1988; 32: 15-20.

28 Eintrei $C$, Leszniewski $W$, Carlsson C. Local application of ${ }^{133}$ Xenon for measurement of regional cerebral blood flow (rCBF) during halothane, enflurane, and isoflurane anesthesia in humans. Anesthesiology 1985; 63: 391-4.

29 Bissonnette $B$, Lerman $J$. Single breath end-tidal $\mathrm{CO}_{2}$ estimates of arterial $\mathrm{PCO}_{2}$ in infants and children. Can J Anaesth 1989; 36: 2-4.

30 Nunn JF. Carbon Dioxide. In: Nunn JF (Ed.). Applied Respiratory Physiology. 2nd ed., London: Butterworths, 1977; 356-8.

31 Eger EI. Uptake of Inhaled Anaesthetics: The Alveolar to Inspired Anaesthetic Difference. In: Eger EI (Ed.). Anesthetic Uptake and Action. Baltimore: Williams and Wilkins, 1974: 88-94.

32 Tominaga S, Strandgaard S, Uemura $K$ et al. Cerebrovascular $\mathrm{CO}_{2}$ reactivity in normotensive and hypertensive man. Stroke 1976; 7: 507-10.

33 Ackerman RH, Zilkha E, Bull JW et al. The relationship of the $\mathrm{CO}_{2}$ reactivity of cerebral vessels to blood pressure and mean resting blood flow. Neurology 1973; 23: 21-6.

34 Greisen $G$. Analysis of cerebroarterial Doppler flow velocity waveforms in newborn infants: towards an index of cerebrovascular resistance. J Perinat Med 1986; $14 ; 181-7$.

35 Gray PH, Griffin EA, Drumm JE, Fitzgerald DE, Duignan $N M$. Continuous wave Doppler ultrasound evaluation of cerebral blood flow in neonates. Arch Dis Child 1983; 58: 677-81.

36 Arnolds BJ, Von Reutern GM. Transcranial Doppler sonography. Examination technique and normal reference values. Ultrasound Med Biol 1986; 12: 115-23.

37 Winkler $P$, Helmke $K$. Major pitfalls in Doppler investigations with error, resulting pitfalls and measures to prevent errors. Pediatr Radiol 1990; 20: 219--28.

38 Werner $C$. Transcranial Doppler sonography: trend monitor of cerebral hemodynamics? J Neurosurgical Anesthesiology 1991; 3: 73-6.
39 Aaslid $R$, Lindegaard K-F, Sorteberg W, Nomes $H$. Cerebral autoregulation dynamics in humans. Stroke 1989; 20: 45-52.

40 Aaslid $R$. Visually evoked dynamic blood flow response of the human cerebral circulation. Stroke 1987; 18: 771-5.

41 Giller CA. Transcranial Doppler monitoring of cerebral blood flow velocity during craniotomy. Neurosurgery 1989; 25: 769-76.

42 Giller CA, Bowman G, Hunter D, Mootz L, Krippner $W$. Diameter changes in cerebral arteries during craniotomy. 1990; 9: 301.

43 Strandgaard S, Paulson $O B$. Cerebral autoregulation. Stroke 1984; 15: 413-6.

44 Padayachee TS, Gosling RG, Bishop CC, Burnand K, Browse NL. Monitoring middle cerebral artery blood flow velocity during carotid endarterectomy. Br J Surg 1986; 73: 98-100.

45 Halsey JM, McDowell HA, Gelmon S, Morawetz $R B$. Blood flow velocity in the middle cerebral artery and regional cerebral blood flow during carotid endarterectomy. Stroke 1989; 20: 53-8.

46 Albin MS, Hantler C, Bunegin L et al. Intracranial air embolism is detected by the transcranial Doppler (TCD) during cardiopulmonary bypass procedures. Anesthesiology 1990; 73: A458.

47 Taylor RH, Borrows FA, Bissonnette B. No flow during low-flow cardiopulmonary bypass. J Thorac Cardiovasc Surg 1991; 101: 362-4.

48 Werner C, Kochs E, Rau M, Schulte am Esch J. Transcranial Doppler as a supplement in the detection of cerebral circulatory arrest. J Neurosurg Anesthesiol 1990; 2: 159-65. 